\title{
Two-factor Analysis on Compressive Strength of Recycled Aggregate Concrete
}

\author{
Chunling YAN \\ School of Civil and Architectural Engineering \\ Anyang institute of technology \\ Henan, China \\ e-mail: yanchunling2003@163.com
}

\author{
Yongtao SHI \\ School of Civil and Architectural Engineering \\ Anyang institute of technology \\ Henan, China \\ e-mail: 191871615@QQ.com
}

\begin{abstract}
Recycled coarse aggregate (RCA) was obtained from waste samples of $\mathrm{C30}$ in the laboratory through crushing, washing and screening and cube compressive strength test was conducted on RCA concrete under different conditions. The results show that the compressive strength of recycled aggregate concrete (RAC) decreases with the amounts of RCA generally increase of the replacement ratio on recycled aggregate in the same water-cement ratio. However, when the replacing $50 \%$ the natural coarse aggregate (NCA), the compressive strength of RAC appears to jump. Two-factor analysis is used to arrange the experiment by taking a full consideration of the factors which have effect on the compressive strength, such as water-cement ratio, coarse aggregate replacement ratio, and the interaction between water-cement ratio and replacement ratio. The analysis of variance is established and is used to analyze the influence rate of the compressive strength. It also shows that main factor which affects the compressive strength is coarse aggregate replacement ratio and the interaction function on the watercement and replacement ratio cannot be ignored. The study offers a valuable reference to the design of recycled concrete. This electronic document is a "live" template. The various components of your paper [title, text, heads, etc.] are already defined on the style sheet, as illustrated by the portions given in this document.
\end{abstract}

Keywords-recycled coarse aggregate; compressive strength; concrete; the analysis of variance

\section{INTRODUCTION}

With the rapid development of society and economy, natural resources are depleting in the earth. Especially procurement of these natural materials extremely modifies the natural sources and creates major environmental problems [1-2]. Taking the construction industry as an example, every year 15 billion tonnes of concrete are produced throughout the world that means 2 tonnes of concrete per inhabitant per year [3]. Furthermore, the quality of coarse aggregate accounted for about $55 \%$ of the total. It can be seen that aggregate consumption is huge, and one day coarse aggregate will be exhausted, like other mineral resources. Currently, these waste concrete is often disposed in open-air stacking or landfill manner. Therefore, this not only takes up a lot of land, but also causes environmental pollution and waste of resources.

As early as 1946, Gluzhge [4], the former Soviet Union scholar, the feasibility of using waste recycled aggregate concrete was studied. In the middle of 20th century, Japan, the United States and some European countries have begun the research and the utilization of recycled concrete and the study focuses mainly on the mechanical properties of RAC [5-7]. Hansen [8] conducted related research on the compressive strength of recycled concrete and found that the compressive strength of recycled concrete roughly $5 \%$ to $24 \%$ lower than ordinary concrete. Limbachiya et al. [9] drew a conclusion that compressive strength of recycled concrete was lower than that of ordinary concrete, reducing the range of $15 \%-42 \%$. Salomon [10] found that the compressive strength of recycled concrete was lower than that of ordinary concrete by test. However, Xiao [11] and Huang [12] believe that the compressive strength of recycled concrete is almost the same with that of ordinary concrete when the replacement ratio of coarse aggregate is no more than $30 \%$. Folino [13] and Tavakoli [14] argue that a reasonable proportion of recycled aggregate can make cube compressive strength of recycled concrete be higher than that of ordinary concrete under the same water-cement ratio.

At present, numerous studies have been carried out by researchers on the relationship with the compressive strength of RCA concrete and replacement ratio of coarse aggregate or water-cement ratio and so on, and corresponding results are obtained. However, so far it is not really clear that which factor plays a major role in the compressive strength of RCA and whether the interaction of these factors also affects the compressive strength. This paper discusses these factors of influencing compressive strength, such as replacement ratio, water-cement ratio and the interaction of two factors by use of universal testing machine. This research is of great theoretical value to the design of recycled concrete.

\section{EXPERIMENTAL DESIGN}

\section{A. Preparation of Coarse Aggregate}

This experiment adopts P. O 42.5 ordinary Portland cement, natural river sand, tap water, and coarse aggregate (the mixture of crushed stone and RCA). Coarse aggregate is continuous gradation and the range of particle size is 5$31.5 \mathrm{~mm}$. 
TABLE I. Principal Physical Properties of Recycled CoARSe AgGREgate

\begin{tabular}{|c|c|c|c|c|c|}
\hline $\begin{array}{c}\text { Apparent density } \\
/ \mathbf{k g . m}^{-3}\end{array}$ & $\begin{array}{c}\text { Water absorption } \\
\text { ratio /\% }\end{array}$ & $\begin{array}{c}\text { Crushing value } \\
/ \%\end{array}$ & $\begin{array}{c}\text { Bulk density } \\
/ \mathbf{k g . \mathbf { m } ^ { - 3 }}\end{array}$ & $\begin{array}{c}\text { Porosity } \\
/ \%\end{array}$ & $\begin{array}{c}\text { Mud content } \\
\mathbf{/ \%}\end{array}$ \\
\hline 2200 & 6.16 & 14.7 & 1760 & 42 & 1.5 \\
\hline
\end{tabular}

Recycled coarse aggregate, with large porosity, large absorption, low strength, and so on, compared with natural aggregate. Thus, the features limit the application of recycled concrete in some engineering. According to national standard GB/T25177-2010 concrete with recycled coarse aggregate, RCA was obtained from waste samples of C30 in the laboratory through crushing, washing and screening. The main physical properties of RCA were presented in Table 1.

\section{B. Compressive Strength Test}

Firstly, in accordance with the law of Chinese industry standard JGJ52-2006 quality standards and test methods of ordinary concrete, C30 concrete mix proportions were calculated. Secondly, according to the experimental specification mixing concrete, the mixed concrete was put into $150 \times 150 \times 150 \mathrm{~mm}$ mold testing and placed in the curing room. After curing $28 \mathrm{~d}$, loading tests are carried out to these concrete samples by WEW-1000A universal testing machine.

\section{Two-FACTOR TEST DESIGN AND TEST RESUltS}

\section{A. Introduction on Two-factor Test Design}

Two-factor analysis of the experiment is to discuss two factors significantly affecting the test results. Thus, it is known as binary analysis of variance. According to test times, two-factor test method can be divided into no repeat test and repeated test analysis of variance. The paper adopts the analysis of variance of repeated test.

\section{B. Experiment Program and Test Results}

Two-factors are mainly considered in the design; one is water-cement ratio, and the other is replacement ratio of coarse aggregate. Three levels $0.43,0.49$ and 0.55 were considered to water-cement ratio. Simultaneously, five levels $0 \%, 30 \%, 50 \%, 70 \%$ and $100 \%$ were studied to replacement ratio of coarse aggregate. Test results are shown in Table 2.

TABLE II. CONCRETE COMPRESSIVE STRENGTH OF CONCRETE UNDER DIFFERENT WATER-CEMENT RATIO AND REPLACEMENT RATIO/MPA

\begin{tabular}{|c|c|c|c|c|c|c|}
\hline \multicolumn{2}{|c|}{ Factor } & \multicolumn{5}{|c|}{ Replacement ratio of coarse aggregate /\% } \\
\cline { 3 - 7 } & & $\mathbf{0}$ & $\mathbf{3 0}$ & $\mathbf{5 0}$ & $\mathbf{7 0}$ & $\mathbf{1 0 0}$ \\
\hline \multirow{4}{*}{\begin{tabular}{c}
\multirow{3}{*}{ Water- } \\
cement
\end{tabular}} & 37.9 & 33.1 & 35.3 & 30.2 & 29.5 \\
ratio & \multirow{3}{*}{0.49} & 38.7 & 33.9 & 34.4 & 29.6 & 29.1 \\
& & 38.2 & 33.4 & 34.6 & 30.1 & 28.8 \\
\cline { 3 - 7 } & & 37.6 & 30.9 & 35.5 & 30.2 & 28.4 \\
& & 37.1 & 31.8 & 35.8 & 29.5 & 28.9 \\
& \multirow{3}{*}{0.55} & 34.9 & 29.3 & 35.7 & 29.9 & 28.6 \\
\hline & & 35.3 & 29.8 & 33.4 & 27.9 & 27.2 \\
& & 35.5 & 30.2 & 32.8 & 28.2 & 26.9 \\
\hline
\end{tabular}

\section{VARIANCE ANALYSIS OF TEST RESUlts}

The influence rate is established by mathematical statistics method and the effect of two parameters (watercement and replacement ratio of RCA) on the compressive strength is studied according to test results.

In general, there are two varied factors $A$ and $B$, where $A$ and $B$, respectively, have $r$ levels and $s$ levels, $A_{1}, A_{2} \ldots A_{r}$ and $B_{1}, B_{2} \ldots B_{s}$. To study the interaction influence of $A \times B$, repeated experiments were done in each combination level $\left(A_{i}, B_{j}\right)$ and each test value was recorded as $x_{i j k}(i=1,2, \ldots, r$; $j=1,2, \ldots, s ; k=1,2, \ldots, c)$. Therefore, the total times of tests apparently are $n=r s c$.

The steps of two-factor variance analysis are as follows. Abbreviations and Acronyms

A. Calculating the Mean

Assuming:

$$
\bar{x}=\frac{1}{r s c} \sum_{i=1}^{r} \sum_{j=1}^{s} \sum_{k=1}^{c} x_{i j k}
$$

$$
\bar{x}_{i j \bullet}=\frac{1}{c} \sum_{k=1}^{c} x_{i j k}, i=1,2, \cdots, r ; j=1,2, \cdots, s
$$

$$
\overline{x_{i \bullet \bullet}}=\frac{1}{s c} \sum_{j=1}^{s} x_{i j k}=\frac{1}{s} \sum_{j=1}^{s} \bar{x}_{i j \bullet, i}=1,2, \cdots, r
$$

$$
x_{\bullet j \bullet}=\frac{1}{r c} \sum_{i=1}^{r} x_{i j k}=\frac{1}{r} \sum_{i=1}^{r} \bar{x}_{i j \bullet}, j=1,2, \cdots, s
$$

where $\bar{x}, \bar{x}_{i j \bullet}, \bar{x}_{i \bullet \bullet}$ and $\bar{x}_{\bullet j \bullet}$ are the arithmetic mean of all test values, the arithmetic mean of any combination $\left(A_{i}, B_{j}\right)$ level on $C$ tests, the arithmetic mean of all values in $A_{i}$ levels, and the arithmetic mean of all values in $B_{j}$ levels, respectively. 


\section{B. Calculating Square Sum of Total Deviation}

1) Square sum of total deviation

$$
S S_{\mathrm{T}}=\sum_{i=1}^{r} \sum_{j=1}^{s} \sum_{k=1}^{c}\left(x_{i j k}-\bar{x}\right)^{2}=S_{\mathrm{A}}+\mathrm{SS}_{\mathrm{B}}+\mathrm{SS}_{\mathrm{A} \times \mathrm{B}}+\mathrm{SS}_{\mathrm{e}}
$$

where $S S_{\mathrm{A}}, S S_{\mathrm{B}}, S S_{\mathrm{A} \times \mathrm{B}}$ and $S S_{\mathrm{e}}$ are square sum of deviation by factor $A$, square sum of deviation by factor $B$, square sum of deviation by interaction $A \times B$, and residual sum of squares, respectively. In Equation 5, SS $=s c \sum_{i=1}^{r}\left(\bar{x}_{i \bullet \bullet}-\bar{x}\right)^{2}$, $S S_{\mathrm{B}}=r c \sum_{j=1}^{s}\left(\bar{x}_{\bullet j \bullet}-\bar{x}\right)^{2}, S S_{\mathrm{A} \times \mathrm{B}}=c \sum_{i=1}^{r} \sum_{j=1}^{s}\left(\bar{x}_{i j \bullet}-\bar{x}_{i \bullet \bullet}-\bar{x}_{\bullet \bullet \bullet}+\bar{x}\right)^{2}$ and $S S_{\mathrm{e}}=\sum_{i=1}^{r} \sum_{j=1}^{s} \sum_{k=1}^{c}\left(x_{i j k}-\bar{x}_{i j \bullet}\right)^{2}$.

2) Square sum of deviation on each factor: The simplified formulas are as follows:

$$
\begin{gathered}
T_{i j \bullet}=\sum_{k=1}^{c} x_{i j k} \\
T_{i \bullet \bullet}=\sum_{j=1}^{s} \sum_{k=1}^{c} x_{i j k} \\
T_{\bullet} \bullet=\sum_{i=1}^{r} \sum_{k=1}^{c} x_{i j k} \\
T=\sum_{i=1}^{r} \sum_{j=1}^{s} \sum_{k=1}^{c} x_{i j k} \\
Q=\sum_{i=1}^{r} \sum_{j=1}^{s} \sum_{k=1}^{c} x_{i j k}^{2}
\end{gathered}
$$

where $T_{i j \bullet}, T_{i \bullet \bullet}, T_{\bullet j \bullet}, T$ and $Q$ are Sum of experimental values of any combination $\left(A_{i}, B_{j}\right)$ level on $C$ tests, the sum of $s c$ experimental values on level $A_{i}$, the sum of $r c$ experimental values on level $B_{j}$, the sum of $n$ experimental values, and squares sum of $n$ experimental values, respectively. Then, each simplified formula of square sum of deviation is as follows.

$$
\begin{gathered}
S S_{\mathrm{T}}=Q-\frac{T^{2}}{n} \\
S S_{\mathrm{A}}=\frac{1}{s c} \sum_{i=1}^{r} T_{i \bullet \bullet}^{2}-\frac{T^{2}}{r s c}=\frac{1}{s c} \sum_{i=1}^{r} T_{i \bullet \bullet}^{2}-\frac{T^{2}}{n} \\
S S_{\mathrm{B}}=\frac{1}{r c} \sum_{j=1}^{s} T_{\bullet j \bullet}^{2}-\frac{T^{2}}{r s c}=\frac{1}{r c} \sum_{j=1}^{s} T_{\bullet j \bullet}^{2}-\frac{T^{2}}{n} \\
S S_{\mathrm{e}}=Q-\frac{1}{c} \sum_{i=1}^{r} \sum_{j=1}^{s} T_{i j \bullet} \\
S S_{\mathrm{A} \times \mathrm{B}}=S S_{\mathrm{T}}-S S_{\mathrm{A}}-S S_{\mathrm{B}}-S S_{\mathrm{e}} \\
\text { Degrees of Freedom } \\
\text { Degrees of freedom on factor } A \\
d f_{\mathrm{A}}=r-1
\end{gathered}
$$

C. Degrees of Freedom

Degrees of freedom on factor $B$

$$
d f_{\mathrm{B}}=s-1
$$

Degrees of freedom on $A \times B$

$$
d f_{\mathrm{A} \times \mathrm{B}}=(r-1)(s-1)
$$

Degrees of freedom on residuals

$$
d f_{\mathrm{e}}=r s(c-1)
$$

Total degrees of freedom

$$
d f_{\mathrm{T}}=n-1=r s c-1
$$

where $d f_{\mathrm{A}}, S S_{\mathrm{B}}, S S_{\mathrm{A} \times \mathrm{B}}, d f_{\mathrm{e}}$, and $d f_{\mathrm{T}}$ are degrees of freedom on factor $A$, factor $B, A \times B$, residuals and total, respectively.

D. Mean Squares

Mean square of factor $A$

$$
M S_{\mathrm{A}}=\frac{S S_{\mathrm{A}}}{r-1}
$$

Mean square of factor $B$ 


$$
M S_{\text {B }}=\frac{S S_{\text {B }}}{s-1}
$$

Mean square of the interaction

$$
M S_{\mathrm{A} \times \mathrm{B}}=\frac{S S_{\mathrm{A} \times \mathrm{B}}}{(r-1)(s-1)}
$$

Mean square of residuals

$$
M S_{\mathrm{e}}=\frac{S S_{\mathrm{e}}}{r s(c-1)}
$$

E. F Value

$$
\begin{gathered}
F_{\mathrm{A}}=\frac{M S_{\mathrm{A}}}{M S_{\mathrm{e}}} \\
F_{\mathrm{B}}=\frac{M S_{\mathrm{B}}}{M S_{\mathrm{e}}} \\
F_{\mathrm{A} \times \mathrm{B}}=\frac{M S_{\mathrm{A} \times \mathrm{B}}}{M S_{\mathrm{e}}}
\end{gathered}
$$

where $F_{\mathrm{A}}, F_{\mathrm{B}}$ and $F_{\mathrm{A} \times \mathrm{B}}$ are $F$ value of factor $A, F$ value of factor $B, F$ value of the interaction $A \times B$.

\section{F. Significance Test}

Given test level $\alpha$, the critical value $F_{1-\alpha}\left(d f_{j}, d f_{e}\right)$ is found out from the $F$ distribution table and $F$ values $F\left(d f_{j}, d f_{e}\right)$ will be calculated by formula (25-27). If $F\left(d f_{j}, d f_{e}\right) \geq F_{1-\alpha}\left(d f_{j}, d f_{e}\right)$, the influence of the factor on the test is significant. Further, the greater is the values $F\left(d f_{j}, d f_{e}\right)$, the more significant is the influence of the factor. Meanwhile, the influence rate $\delta$ is defined as follows:

$$
\delta=\frac{F\left(d f_{j}, d f_{e}\right)}{F_{1-\alpha}\left(d f_{j}, d f_{e}\right)}
$$

\section{G. The Influence Ratio of Each Factor on Concrete Compression Strength}

According to the steps above, the data of Table 2 was calculated; the results are shown in Table 3. Given the test level $\alpha=0.05, F_{1-0.05}(2,30)=3.32, F_{1-0.05}(4,30)=2.69$, $F_{1-0.05}(8,30)=2.27$ are obtained from $F$ distribution table. If $\delta \geq 1$, it indicates that the parameter has a significant influence on the compressive strength of recycled concrete. As can be seen from Table 3, the water-cement ratio, the replacement ratio of coarse aggregate, and their interaction on recycled concrete have a significant influence on compressive strength of recycled concrete. Further, the influence of the replacement of coarse aggregate is even larger and the interaction on the replacement of coarse aggregate and water-cement ratio can not be ignored.

TABLE III. ANALYSIS OF THE INFLUENCE RATE OF EACH FACTOR ON CONCRETE COMPRESSION STRENGTH

\begin{tabular}{|c|c|c|c|c|c|}
\hline $\begin{array}{c}\text { Source of } \\
\text { Variance }\end{array}$ & $\boldsymbol{S S}$ & $\boldsymbol{d} \boldsymbol{f}$ & $\boldsymbol{M S}$ & $\boldsymbol{F}$ & $\boldsymbol{\delta}$ \\
\hline Factor $A$ & 49.152 & 2 & 24.576 & 221.206 & 66.628 \\
\hline Factor $B$ & 456.241 & 4 & 114.060 & 1026.643 & 381.652 \\
\hline$A \times B$ & 9.983 & 8 & 1.248 & 11.233 & 4.948 \\
\hline Error & 3.333 & 30 & 0.111 & - & - \\
\hline Total & 518.709 & 44 & - & - & - \\
\hline \multicolumn{7}{|c|}{ Note: $A$ - water-cement ratio; $B$ - the replacement ratio of coarse aggreg }
\end{tabular}

\section{CONCLUSION}

Based on the compressive strength test of recycled concrete under the replacement of coarse aggregate and different water-cement ratio, combined with analysis of variance, the following conclusions were drawn:

- Recycling of waste concrete compared with ordinary concrete can greatly reduce production costs and significantly improve the utilization of waste concrete. From the requirements of the concrete compressive strength in the construction, the replacement rate of $50 \%$ coarse aggregate is recommended to use waste concrete.

- Avoid combining SI and CGS units, such as current in amperes and magnetic field in oersteds. This often leads to confusion because equations do not balance dimensionally. If you must use mixed units, clearly state the units for each quantity that you use in an equation.

- Through the two-factor repeated test and analysis of variance, the result shows that main factor which affects the compressive strength is the replacement ratio of coarse aggregate and the interaction function on the water-cement and the replacement ratio cannot be ignored.

\section{ACKNOWLEDGMENT}

This investigation is supported by the Key Scientific Research Projects of Universities in Henan Province in 2016, Project No. 
16B560001. The authors are deeply indebted to the financial supporters.

\section{REFERENCES}

[1] M. L. Berndt, "Properties of sustainable concrete containing fly ash, slag and recycled concrete aggregate," Constr Build Mater, vol. 23, 2009, pp. 2606-2613.

[2] Ö. Çakır, "Experimental analysis of properties of recycled coarse aggregate (RCA) concrete with mineral additives", Constr Build Mater ,vol. 68, 2014, pp.17-25.

[3] B. H. Sumaiya, and A. M. Shahria, "Mechanical behavior of three generations of $100 \%$ repeated recycled coarse aggregate concrete," Constr Build Mater ,vol. 65, 2014, pp.574-582.

[4] P. J. Gluzhge, "The work of scientific research institute", Gidrotekhnicheskoye Stroitel' stvo, vol. 4, 1946, pp: 27-28.

[5] L. Evangelista, and D. J. Brito, "Mechanical behavior of concrete made with fine recycled concrete aggregates," J. Cement \& Concrete Composites, vol. 29, 2007, pp.397-401.

[6] S. W. Tabsh, and A. S. Abdelfatah, "Influence of recycled concrete aggregates on strength properties of concrete", Construction and Building Materials, vol. 23, 2009, pp. 1163-1167.

[7] K. K. Sagoe-Crentsil, T. Brown, and A. H. Taylor, "Performance of concrete made with commercially produced coarse recycled concrete aggregate", Cement and Concrete Research, vol. 31, 2001, pp. 707712.

[8] T. C. Hansen, "Recycling of demolished concrete and masonry", London: E \& FN Spon press, 1992, 37-41.

[9] M. C. Limbachiya, T. Leelawat, and R. K. Dhir, "Use of recycled concrete aggregate in high-strength concrete", Materials and Structures, vol. 33, 2000, pp. 574-580.

[10] M. L. Salomon,and H. Paulo. "Durability of recycled aggregate: a safe way to sustainable development", Cement and Concrete Research, vol. 34, 2004, pp. 1975-1980.

[11] J. Z. Xiao, B. Lei , and B. Yuan, "Compressive strength distribution of recycled aggregate concrete derived from different origins", Journal of Building Structures, vol. 29, 2008, pp. 94-100.

[12] W. F. Huang, "Experimental study on mechanical properties of concrete with recycled aggregates and admixtures", Harbin: Harbin institute of Technology press, 2007, 7-25.

[13] P. Folino, and H. Xargay, "Recycled aggregate concrete-Mechanical behavior under uniaxial and triaxial compression", Construction and Building Materials, vol. 56, 2014, pp. 21-31.

[14] M. Tavakoli, and P. Soroushian, "Strengths of recycled aggregate concrete made using field-demolished concrete as aggregate", ACI Materials Jounal, 1996, vol. 93, pp. 182-90. 